\title{
Modelling and Prediction of Effect of Machining Parameters on Surface Roughness in Turning Operations
}

\author{
Mustafa ÖZDEMIR
}

\begin{abstract}
In this study, effects of different machining parameters on surface roughness in turning of St-37 material are presented. The machining experiments were carried out on the CNC lathe. In order to minimize the number of experiments, the experimental design was set up using Taguchi's $L 27$ orthogonal array. Cutting speed (150 $\mathrm{m} / \mathrm{min}$, $200 \mathrm{~m} / \mathrm{min}$, and $250 \mathrm{~m} / \mathrm{min})$, feed rate $(0,1 \mathrm{~mm} / \mathrm{rev}, 0,2 \mathrm{~mm} / \mathrm{rev}$, and $0,3 \mathrm{~mm} / \mathrm{rev})$, depth of cut $(0,5 \mathrm{~mm}, 1 \mathrm{~mm}$, and $1,5 \mathrm{~mm})$, and tool nose radius $(0,4 \mathrm{~mm}, 0,8 \mathrm{~mm}$ and 1,2 $\mathrm{mm}$ ) were used as control factors. The analysis of variance (ANOVA) was performed in order to determine the impact of the control factors on surface roughness. Signal/noise $(S / N)$ ratios were determined in the Taguchi design. The results of the regression models and Taguchi Analysis revealed that the most effective parameters on surface roughness $(R a$ and $R z)$ were the feed rate $(f)$ and tool nose radius $(R)$.
\end{abstract}

Keywords: analysis of variance; cutting parameters; surface roughness; Taguchi method

\section{INTRODUCTION}

Machining is an operation of forming the desired geometry by performing chip removal over the material. Hence, the appropriate material, tools, and lathes should be used in order to achieve this operation. One important branch of machining is the operation of turning, whereby the piece is given the desired shape and form by machining over a rotating material via cutting tool $[1,2]$. Machining has an important place among other manufacturing methods. Among all manufacturing methods, a good surface quality of a product is as important as its dimensional and geometric tolerances. Surface roughness is mainly dependent on the result of machining parameters such as tool geometry (i.e. nose radius, cutting edge geometry, clearance angle etc.) and cutting conditions (i.e. feed rate, cutting speed, depth of cut, etc.) [3-5]. Surface structure of the machine parts is affected directly by change in any of the work piece, cutting tool, machining conditions, or the lathe; namely the machining regime, [6$8]$.

When examining the studies on values of surface roughness occurring based on cutting parameters in $\mathrm{CNC}$ turning operations, numerous studies have been found Yang et al., investigated the experimental results obtained by using cutting parameters such as cutting speed, feed rate and depth of cut for the finish turning of a titanium alloy (TC 11) material, via the response surface methodology (RSM) [9]. Ramesh et al., conducted a similar study on turning of titanium alloy (gr5) [10]. Davim investigated the correlation between cutting speed, feed rate, depth of cut, and surface roughness in the turning operation by using Taguchi technique and determined that especially feed rate was significantly effective on surface roughness [11]. Günay and Yücel used the surface roughness values obtained from machining a high alloy casting material (50 $\mathrm{HRC}$ and $62 \mathrm{HRC}$ ) in order to optimize cutting conditions (i.e. cutting speed, feed rate, and depth of cut). Optimal conditions were determined using the $S / N$ ratio [12]. Bouacha et al., conducted a study on statistical analysis of surface roughness and cutting forces in hard turning of AISI 52100 bearing steel using RSM. ANOVA was used to analyze the effect of cutting forces and cutting parameters affecting surface roughness [13]. Lalwani et al., conducted a similar study. Several RSM tests have been conducted and linear and quadratic models have been established concerning the correlation between the parameters [14]. Asilturk \& Çunkaş carried out a study on estimating and modelling of surface roughness during turning operations using artificial neural networks and multiple regression method. They examined the effect of cutting parameters on surface roughness [15]. Agrawal et al., studied on estimation of the surface roughness of AISI 4340 steel during hard turning [16]. In their study, Routara et al., used RSM and genetic algorithms in order to optimize the cutting conditions for surface roughness parameters during $\mathrm{CNC}$ turning operations [17]. In their study, Selvaraj \& Chandramohan, investigated optimization of the surface roughness of AISI 304 steel during dry turning operations by using the Taguchi method [18]. Sahoo also used RSM and genetic algorithms in order to investigate the optimization of the turning parameters for surface roughness. They confirmed the accuracy of the surface roughness models using Analysis of Variance (ANOVA) [19]. Neşeli et al., conducted a study examining the effect of tool geometry on finish surface in turning of AISI 1040 steel, and analyzed the experimental results via RSM method [20]. Singh \& Rao investigated how cutting conditions and tool geometry impacted surface roughness during finish hard turning [21]. Aouici et al., experimentally examined how the cutting speed, feed rate, work piece hardness, and depth of cut affected both surface roughness and cutting force components in hard turning operations. Mathematical model of these components was developed by using RSM [22]. Makadia and Nanavati studied the effects of feed rate, tool nose radius, cutting speed, and depth of cut on surface roughness of AISI 410 material. The effect of these parameters on surface roughness was examined using RSM [23]. Wang \& Lan used Taguchi orthogonal array together with the Grey Relational Analysis (GRA) considering the cutting speed, depth of cut, feed rate, and tool nose radius [24]. In their study, Noordin et al., subjected AISI 1040 steel material to turning operation using a coated cutter nose and examined 
how the cutting parameters affected the surface roughness. [25]. Deepakkumar \& Sadaiah, on the other hand, examined the effects of different cutting environments (dry, wet, and MQL) on surface roughness and tool wear depending on the parameters of cutting speed and feed rate during turning of AISI 4340 steel. The same researchers also investigated the effect of cutting parameters and determined optimum conditions using ANOVA technique [26]. Xavior \& Adithan conducted a study on determining the effects of cutting fluids on tool wear and surface roughness of AISI 304 steel during turning [27].

This will help the operator to select the cutting parameters with the optimal cutting condition. The research, Taguchi design, is used to design parameters to improve and reduce surface quality and cost of equipment for the cutting process.

In this study, optimization of cutting parameters (i.e. cutting speed, feed rate, depth of cut, tool nose radius) was performed by using Taguchi L27 orthogonal array to examine the effect of cutting parameters on surface roughness during turning operation of St-37 cylindrical material. The cutting parameters yielding the optimum surface roughness values ( $R a$ and $R z$ ) were determined using the Taguchi method, and the correlation between the parameters was then examined. Additionally, the analysis of variance was used to determine the effects of control factors on surface roughness. Finally, the validity of the optimization was tested through confirmation experiments.

\section{MACHINING MECHANICS AND CHIP FORMATION}

Machining is the operation of removing the material in the form of layer over the work piece by using a tool with a sharp nose and force in order to produce a piece a certain size, shape, and surface quality. From physical aspect, machining operation is a complex physical event involving events such as formation of friction heat, the removal and shrinkage of chips, the hardening of the surface of the machined work piece, and the wearing of nose of the tools based on the elastic and plastic deformation. In order to remove a certain material layer from a piece, the tool must penetrate into that material. This only occurs when forces applied to the tool are sufficient and the tool's material is harder than the piece's material [28-30].

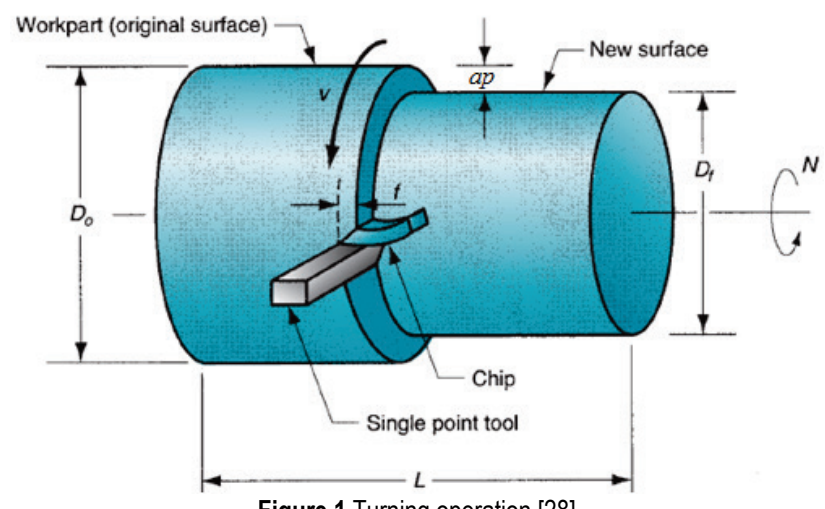

The mechanism required for machining is the occurrence of regional shear deformation on work piece right in front of the cutting edge. During cutting, the relative motion between the work piece and the tool presses the work piece near the tool to form the chips by causing the shear deformation, also called as the first deformation (Fig. 1).

\section{MATERIAL AND METHOD}

In the study, an experimental study was conducted to examine the effect of parameters of three cutting speeds $(150 \mathrm{~m} / \mathrm{min}, 200 \mathrm{~m} / \mathrm{min}$, and $250 \mathrm{~m} / \mathrm{min})$, three feed rates $(0,1 \mathrm{~mm} / \mathrm{rev}, 0,2 \mathrm{~mm} / \mathrm{rev}$, and $0,3 \mathrm{~mm} / \mathrm{rev})$, three depths of cut $(0,5 \mathrm{~mm}, 1 \mathrm{~mm}, 1,5 \mathrm{~mm})$, and three tool nose radius $(0,4 \mathrm{~mm}, 0,8 \mathrm{~mm}, 1,2 \mathrm{~mm})$ on the surface roughness $(R a$ and $R z$ ) in the CNC lathe. The turning experiments were carried out in an Accuway JT-150 CNC turning lathe with a maximum speed of $4500 \mathrm{rpm} . \quad \varnothing 60 \times 360 \mathrm{~mm} \mathrm{St}-37$ material was used in the machining experiments. Tab. 1 shows the chemical composition of the test material used.

Table 1 Properties of St-37 materials used in the experimental study

\begin{tabular}{|c|c|c|c|c|c|c|}
\hline $\mathrm{C} / \%$ & $\mathrm{Si} / \%$ & $\mathrm{Mn} / \%$ & $\mathrm{P} / \%$ & $\mathrm{~S} / \%$ & $\mathrm{Cu} / \%$ & $\mathrm{Mo}$ \\
\hline 0,017 & 0,38 & 1,2 & 0,018 & 0,011 & 0,26 & 0,07 \\
\hline
\end{tabular}

The TAEGUTEG-quality DNMG 150604 FG, DNMG 150608 PC, and DNMG 150612 MT noses were selected for this study. A cutting tool catalog was used in order to determine the tools' cutting parameters. Prior to the experiment, the cutting process was performed in accordance with the values specified in the catalogue in order to provide an opportunity of making a preliminary assessment about cutting parameters. No coolant was used in this study. Fig. 2 shows the flow chart of the experimental study.

The Taguchi method is an effective analysis method used to optimize the machining parameters affecting the production process. The experimental design performed by using this method leads to a significant decrease in number of experiments as well as minimization in time loss.

In the study, the experimental design was performed using Taguchi method and surface roughness ( $R a$ and $R z$ ) was taken as a basis as quality properties. The control factors were determined as cutting speed $(\mathrm{m} / \mathrm{min})$, feed rate $(\mathrm{mm} / \mathrm{rev})$, depth of cut $(\mathrm{mm})$, and tool nose radius $(\mathrm{mm})$. Each control factor was identified at three levels according to the Taguchi L27 orthogonal array. Tab. 2 shows the control factors and their levels.

Table $2 \mathrm{~A}$ four factor and three level design for experimentation

\begin{tabular}{|l|c|c|c|}
\hline \multicolumn{1}{|c|}{ Process parameters } & 1. Level & 2. Level & 3. Level \\
\hline Cutting speed, $v$ & 150 & 200 & 250 \\
\hline Feed rate, $f$ & 0,1 & 0,2 & 0,3 \\
\hline Depth of cut, $a p$ & 0,5 & 1 & 1,5 \\
\hline Tool nose radius, $R$ & 0,4 & 0,8 & 1,2 \\
\hline
\end{tabular}

The L27 orthogonal array was created using the Taguchi method in order to eliminate these negativities since carrying out totally $27 \times 3=81$ experiments via full factorial design would lead to cost and time loss. When assessing time and material costs spent for carrying out these experiments, the method being developed by Taguchi and allowing to decrease the number of experiments meets the need [31]. 


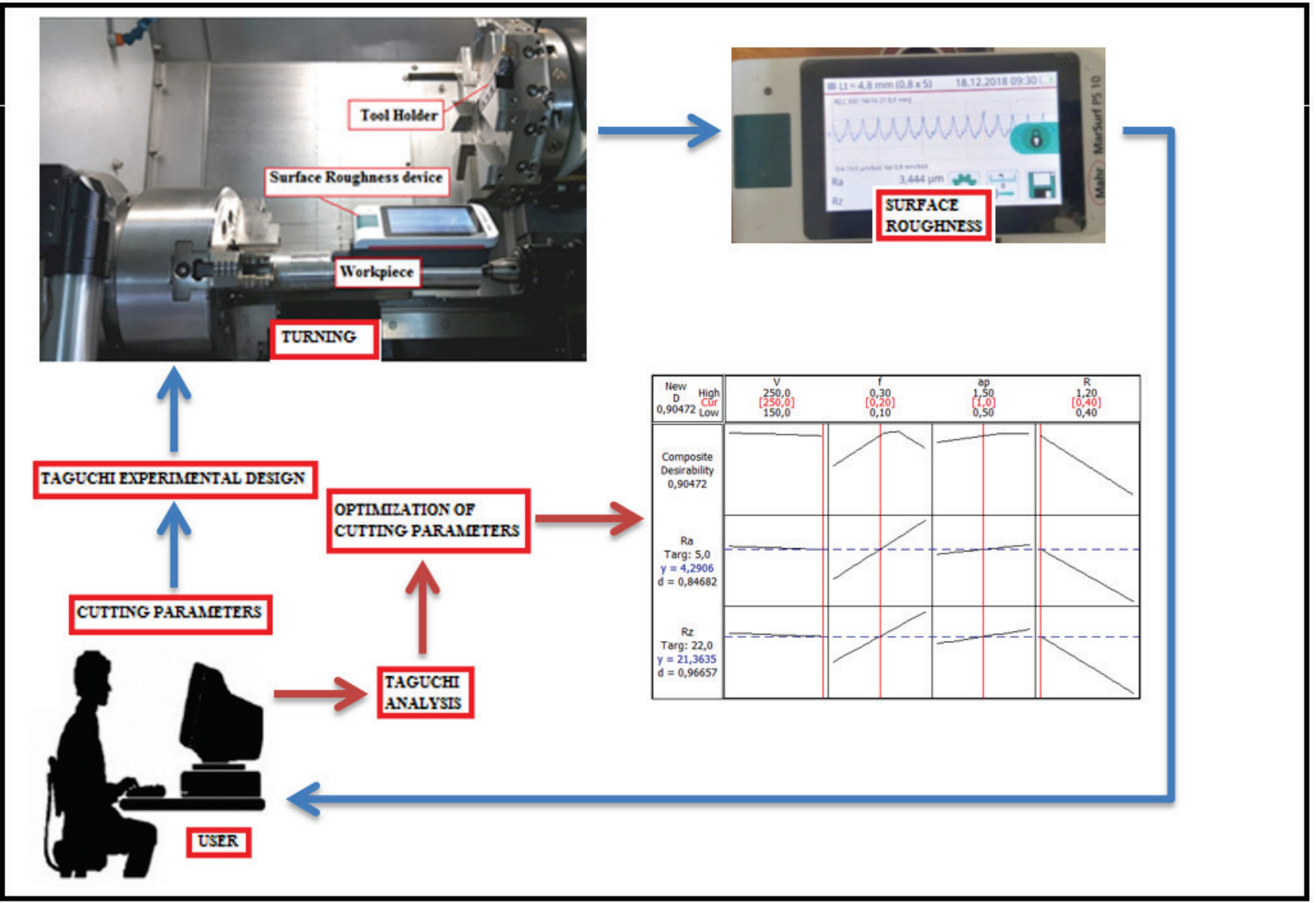

Figure 2 The flowchart for optimisation of cutting parameters

The Taguchi method was used as experimental design and analysis method in the study. A statistical performance measure known as the $S / N$ ratio is used in order to analyze the results of the experiments. The experimental results are converted into the $S / N$ ratio, and then evaluated. In the $S / N$ ratio, $S$ stands for the signal factor and $N$ stands for the noise factor. The signal factor refers to the actual value as extracted from the system, while the noise factor refers to the factors that are not involved in experimental design but influence the results of the experiments. Depending on the characteristic type, three methods, including "nominal is best", "larger is better" and "smaller is better" are used for calculation of the $S / N$ ratios. The formula corresponding to "smaller is better" principle in Eq. (1) was used in this study in order to determine the $S / N$ values since the smallest surface roughness values were requested [32-34].

$S / N=-10 \log \left(\frac{1}{n} \sum_{i=1}^{n} Y_{i}^{2}\right)$

The experimental design was performed using the cutting parameters and the Taguchi $L 27$ orthogonal array in Tab. 3. Tab. 3 shows the Taguchi L27 experimental design prepared using Minitab 16 software.

After the experiments, a Mahr MarSurf PS 10 device was used to measure the surface roughness values of the machined surfaces.

Measurements with $12 \mathrm{~mm}$ intervals were taken at three points on the surfaces of the machined piece. All measurements were taken from the highest point on the measurement probe touching the piece while taking the values. After the measurements, the surface roughness values were then obtained by calculating an arithmetic average of the values.

\section{RESULTS AND ANALYSIS}

In the Taguchi method, the $S / N$ ratios are used to determine the optimum levels of the control factors given that great importance is given to decreasing the surface roughness in order to enhance the quality of the product. Tab. 4 shows both the $R a$ and $R z$ values measured as a result of the turning experiments, as well as the $S / N$ ratios calculated.

The $S / N$ response table was used to analyze the effect of each control factor on surface roughness. Tab. 5 shows the $S / N$ response table obtained as a result of the analysis. It shows the optimum levels of control factors for the optimum surface roughness values using the Taguchi technique. The best level for the control factors was found according to the largest $S / N$ ratio among all of the levels of that control factor.

Accordingly, the levels of the factors giving the best $R a$ value alongside $S / N$ ratios were as follows: factor $v$ (Level 3, $S / N=-5,964)$, factor $f$ (Level 1, $S / N=-1,372)$, factor ap (Level 1, $S / N=-5,781$ ), and factor $R$ (Level 3, $\mathrm{S} / \mathrm{N}=-2,557)$. In other words, the optimum $R a$ value was obtained at a cutting speed of $250 \mathrm{~m} / \mathrm{min}(v 3)$, a $0,1 \mathrm{~mm} / \mathrm{rev}$ feed rate $(f 1)$, a depth of cut of $0,5 \mathrm{~mm}(a p 1)$, and a $1,2 \mathrm{~mm}$ tool nose radius (R3), (Fig. 3 ). 
Table 3 Taquchi L27 $\left(3^{4}\right)$ orthogonal array design for experimentation

\begin{tabular}{|c|c|c|c|c|c|c|c|c|c|}
\hline \multirow{2}{*}{ Trial Number } & \multicolumn{4}{|c|}{ Main Cutting Parameters } & \multirow{3}{*}{ Trial Number } & \multicolumn{4}{|c|}{ Main Cutting Parameters } \\
\hline & $v / \mathrm{m} / \mathrm{min}$ & $f / \mathrm{mm} / \mathrm{rev}$ & $a p / \mathrm{mm}$ & $R / \mathrm{mm}$ & & & & & \\
\hline 1 & 150 & 0,1 & 0,5 & 0,4 & & $v / \mathrm{m} / \mathrm{min}$ & $f / \mathrm{mm} / \mathrm{rev}$ & ap $/ \mathrm{mm}$ & $R / \mathrm{mm}$ \\
\hline 2 & 150 & 0,1 & 1,0 & 0,8 & 15 & 200 & 0,2 & 1,5 & 0,8 \\
\hline 3 & 150 & 0,1 & 1,5 & 1,2 & 16 & 200 & 0,3 & 0,5 & 0,4 \\
\hline 4 & 150 & 0,2 & 0,5 & 0,8 & 17 & 200 & 0,3 & 1,0 & 0,8 \\
\hline 5 & 150 & 0,2 & 1,0 & 1,2 & 18 & 200 & 0,3 & 1,5 & 1,2 \\
\hline 6 & 150 & 0,2 & 1,5 & 0,4 & 19 & 250 & 0,1 & 0,5 & 1,2 \\
\hline 7 & 150 & 0,3 & 0,5 & 1,2 & 20 & 250 & 0,1 & 1,0 & 0,4 \\
\hline 8 & 150 & 0,3 & 1,0 & 0,4 & 21 & 250 & 0,1 & 1,5 & 0,8 \\
\hline 9 & 150 & 0,3 & 1,5 & 0,8 & 22 & 250 & 0,2 & 0,5 & 0,4 \\
\hline 10 & 200 & 0,1 & 0,5 & 0,8 & 23 & 250 & 0,2 & 1,0 & 0,8 \\
\hline 11 & 200 & 0,1 & 1,0 & 1,2 & 24 & 250 & 0,2 & 1,5 & 1,2 \\
\hline 12 & 200 & 0,1 & 1,5 & 0,4 & 25 & 250 & 0,3 & 0,5 & 0,8 \\
\hline 13 & 200 & 0,2 & 0,5 & 1,2 & 26 & 250 & 0,3 & 1,0 & 1,2 \\
\hline 14 & 200 & 0,2 & 1,0 & 0,4 & 27 & 250 & 0,3 & 1,5 & 0,4 \\
\hline
\end{tabular}

Table $4 L 27\left(3^{4}\right)$ orthogonal array, experimental results and their $S / N$ ratios

\begin{tabular}{|c|c|c|c|c|c|c|c|c|}
\hline \multirow{2}{*}{$\begin{array}{c}\text { Trial } \\
\text { Number }\end{array}$} & \multicolumn{9}{|c|}{ Main Cutting Parameters } & \multicolumn{2}{c|}{$\begin{array}{c}\text { Measured Surface Roughness } \\
\text { Values }\end{array}$} \\
\cline { 2 - 8 } & $v / \mathrm{m} / \mathrm{min}$ & $f / \mathrm{mm} / \mathrm{rev}$ & $a p / \mathrm{mm}$ & $R / \mathrm{mm}$ & $R a / \mu \mathrm{m}$ & $R z / \mu \mathrm{m}$ & $R a / \mathrm{dB}$ & $R z / \mathrm{dB}$ \\
\hline 1 & 150 & 0,1 & 0,5 & 0,4 & 2,123 & 13,861 & $-6,5390$ & $-22,8357$ \\
\hline 2 & 150 & 0,1 & 1,0 & 0,8 & 1,494 & 8,789 & $-3,4870$ & $-18,8791$ \\
\hline 3 & 150 & 0,1 & 1,5 & 1,2 & 1,420 & 10,601 & $-3,0437$ & $-20,5072$ \\
\hline 4 & 150 & 0,2 & 0,5 & 0,8 & 1,619 & 7,846 & $-4,1849$ & $-17,8933$ \\
\hline 5 & 150 & 0,2 & 1,0 & 1,2 & 1,566 & 8,815 & $-3,8977$ & $-18,9041$ \\
\hline 6 & 150 & 0,2 & 1,5 & 0,4 & 4,531 & 23,706 & $-13,1232$ & $-27,4973$ \\
\hline 7 & 150 & 0,3 & 0,5 & 1,2 & 2,530 & 10,947 & $-8,0613$ & $-20,7862$ \\
\hline 8 & 150 & 0,3 & 1,0 & 0,4 & 7,644 & 34,053 & $-17,6664$ & $-30,6430$ \\
\hline 9 & 150 & 0,3 & 1,5 & 0,8 & 4,195 & 19,738 & $-12,4546$ & $-25,9061$ \\
\hline 10 & 200 & 0,1 & 0,5 & 0,8 & 1,131 & 11,190 & $-1,0667$ & $-20,9766$ \\
\hline 11 & 200 & 0,1 & 1,0 & 1,2 & 0,792 & 5,382 & 2,0255 & $-14,6183$ \\
\hline 12 & 200 & 0,1 & 1,5 & 0,4 & 1,740 & 10,951 & $-4,8093$ & $-20,7893$ \\
\hline 13 & 200 & 0,2 & 0,5 & 1,2 & 1,156 & 5,496 & $-1,2617$ & $-14,8009$ \\
\hline 14 & 200 & 0,2 & 1,0 & 0,4 & 4,142 & 20,212 & $-12,3442$ & $-26,1120$ \\
\hline 15 & 200 & 0,2 & 1,5 & 0,8 & 2,100 & 11,072 & $-6,4458$ & $-20,8843$ \\
\hline 16 & 200 & 0,3 & 0,5 & 0,4 & 7,199 & 31,124 & $-17,1458$ & $-29,8618$ \\
\hline 17 & 200 & 0,3 & 1,0 & 0,8 & 3,685 & 16,901 & $-11,3280$ & $-24,5581$ \\
\hline 18 & 200 & 0,3 & 1,5 & 1,2 & 2,264 & 10,048 & $-7,0975$ & $-20,0419$ \\
\hline 19 & 250 & 0,1 & 0,5 & 1,2 & 0,369 & 2,957 & 8,6516 & $-9,4170$ \\
\hline 20 & 250 & 0,1 & 1,0 & 0,4 & 1,268 & 7,700 & $-2,0624$ & $-17,7294$ \\
\hline 21 & 250 & 0,1 & 1,5 & 0,8 & 1,261 & 8,832 & $-2,0143$ & $-18,9209$ \\
\hline 22 & 250 & 0,2 & 0,5 & 0,4 & 3,478 & 15,986 & $-10,8266$ & $-24,0748$ \\
\hline 23 & 250 & 0,2 & 1,0 & 0,8 & 1,981 & 11,674 & $-5,9377$ & $-21,3444$ \\
\hline 24 & 250 & 0,2 & 1,5 & 1,2 & 1,408 & 7,639 & $-2,9741$ & $-17,6611$ \\
\hline 25 & 250 & 0,3 & 0,5 & 0,8 & 3,799 & 16,711 & $-11,5934$ & $-24,4600$ \\
\hline 26 & 250 & 0,3 & 1,0 & 1,2 & 2,333 & 11,335 & $-7,3571$ & $-21,0887$ \\
\hline 27 & 250 & 0,3 & 1,5 & 0,4 & 9,506 & 47,494 & $-19,5603$ & $-33,5328$ \\
\hline
\end{tabular}

Table 5 Response Table for Signal to Noise Ratios (Smaller is better) for $R a$

\begin{tabular}{|c|c|c|c|c|c|}
\hline Factors & Level 1 & Level 2 & Level 3 & Delta $(\delta)$ & Rank \\
\hline$v$ & $-8,051$ & $-6,608$ & $-5,964$ & 2,087 & 4 \\
\hline$f$ & $-1,372$ & $-6,777$ & $-12,474$ & 11,102 & 1 \\
\hline$a p$ & $-5,781$ & $-6,895$ & $-7,947$ & 2,166 & 3 \\
\hline$R$ & $-11,564$ & $-6,501$ & $-2,557$ & 9,007 & 2 \\
\hline
\end{tabular}

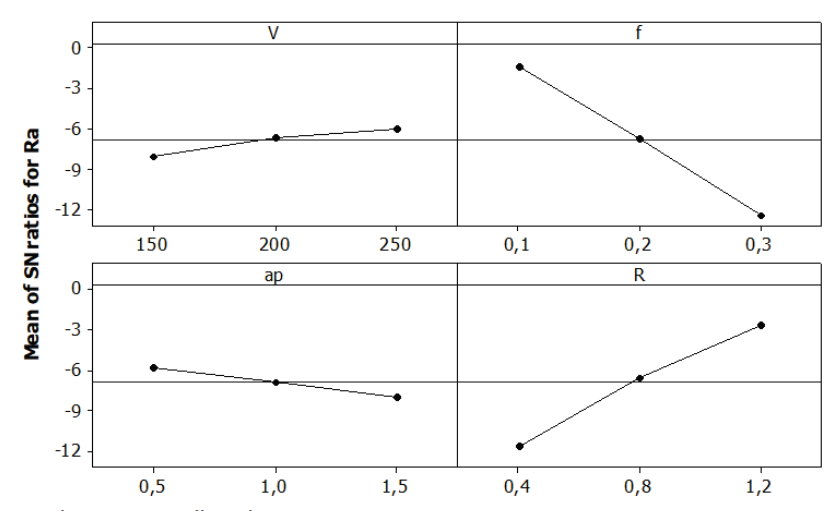

Signal-to-noise: Smaller is better

Figure 3 Main Effects Plot for $S / N$ ratios for $R a$
Table 6 Response Table for Signal to Noise Ratios (Smaller is better) for $R z$ \begin{tabular}{|c|c|c|c|c|c|}
\hline Factors & Level 1 & Level 2 & Level 3 & Delta $(\delta)$ & Rank \\
\hline
\end{tabular}

\begin{tabular}{|c|c|c|c|c|c|}
\hline Factors & Level 1 & Level 2 & Level 3 & Delta $(\delta)$ & Rank \\
\hline$v$ & $-22,65$ & $-21,40$ & $-20,91$ & 1,74 & 4 \\
\hline$f$ & $-18,30$ & $-21,02$ & $-25,65$ & 7,36 & 2 \\
\hline$a p$ & $-20,57$ & $-21,54$ & $-22,86$ & 2,29 & 3 \\
\hline$R$ & $-25,90$ & $-21,54$ & $-17,54$ & 8,36 & 1 \\
\hline
\end{tabular}

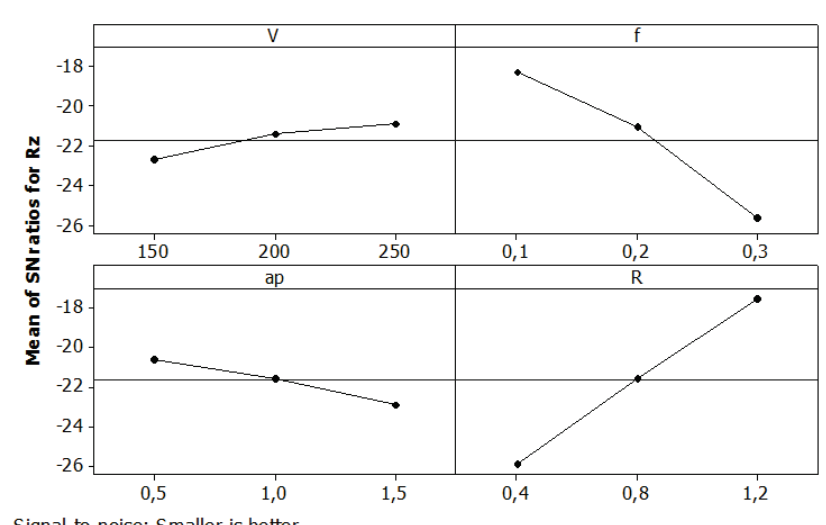

Figure 4 Main Effects Plot for $S / N$ ratios for $R z$ 
The effect of control parameters on the surface roughness $(R z)$ was determined according to the $S / N$ ratios. Tab. 6 shows the level of impact of each factor on $R z$. Fig. 4 shows that level 3 of cutting speed and tool nose radius and level 1 of the feed rate and depth of cut were effective on $R z$.

Figs. 5 and 6 show the surface graphs showing the effects of the machining parameters on surface roughness. It is known that the permanent tension caused during the machining of steel has a significant impact on $R a$ and $R z$. It is also known that as feed rate increases, temperature of cutting region increases and the tool-chip and tool-work piece concentrate on interface of the steel due to low thermal conductivity $[35,36]$. In this context, an increase in Ra values was an expected result (Figs. 5a, 5d, 5e, 6a, $6 \mathrm{~d}$ and $6 \mathrm{e}$ ), given that permanent stresses on the machined surface would increase with increasing feed rate. Therefore, it was determined that there was a direct correlation between surface roughness and feed rate.

The effect of the cutting speed on surface roughness $(R a)$ is shown in 3D surface graphs in Figs. 5a-5c and 6a- 6c. The effect of $f-v, v$-ap and $v$-R cutting parameters on $R a$ and $R z$ is also shown. Figs. $5 \mathrm{a}-5 \mathrm{c}$ and $6 \mathrm{a}-6 \mathrm{c}$ show that cutting speed did not affect the surface roughness too much just as feed rate. Figs. 5b, 5d, $5 f$ and $6 b, 6 d, 6 f$ show the effect of the depth of cut on surface roughness. It appeared that as the depth of cut increased, the surface roughness values increased.

However, it was observed that as the tool nose radius $(R)$ increased, the $R a$ and $R z$ tend to decrease (Figs. 5c, 5e, and $5 \mathrm{f})$. This result can potentially be explained by the formation of chips associated with the thickness of uncut chips decreasing with increasing $R$. Here, it was emphasized that this thickness would diminish along the cutting edge depending on the increase in the radius of the cutting tool [35]. As the thickness of the chips decreased, both the cutting force and therefore the vibration of the cutting tool decreased as well [36]. Accordingly, it was observed that the $R a$ and $R z$ values also decreased due to the increase in $R$ (Figs. 6c, 6e and 6f).
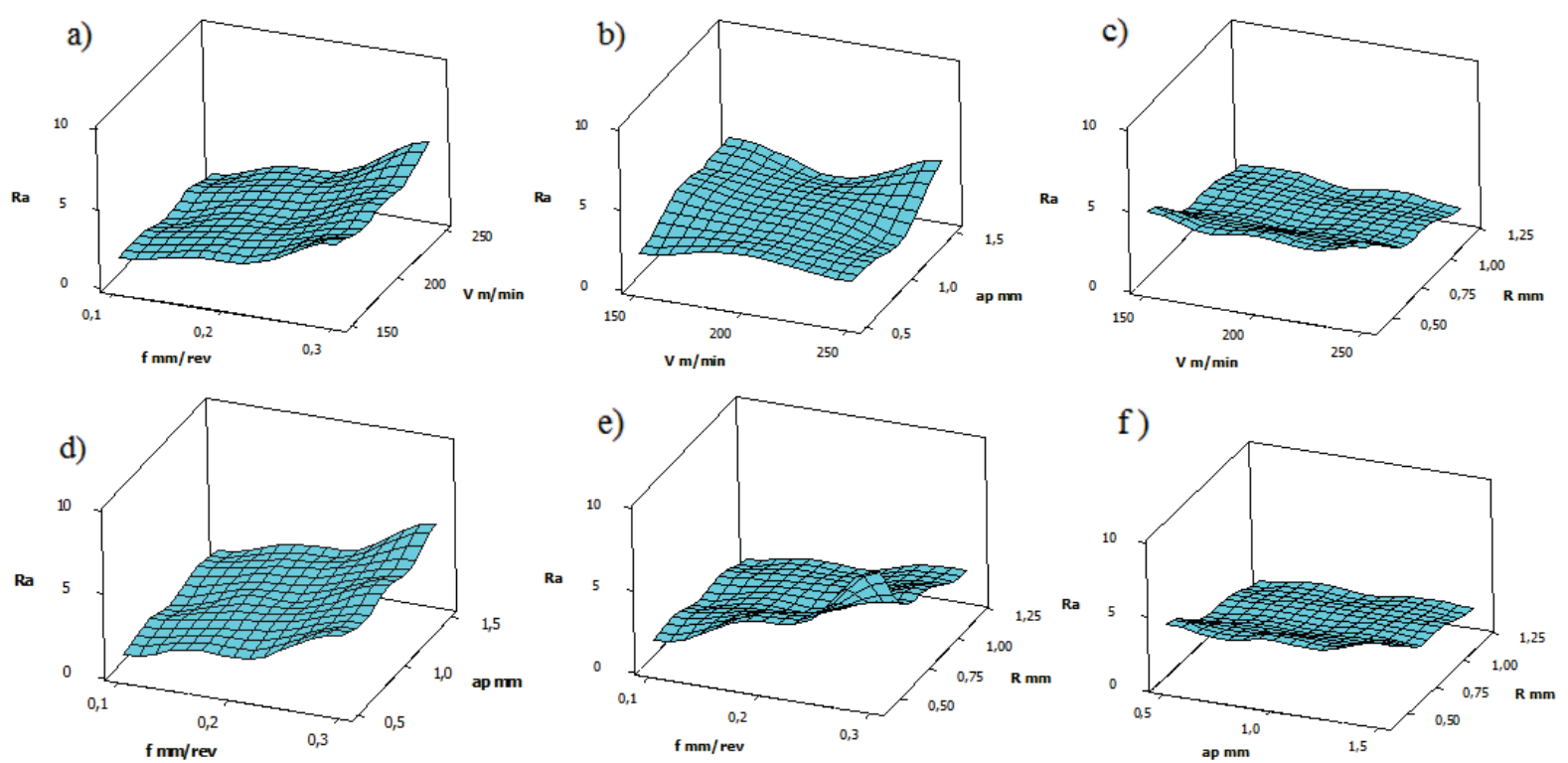

Figure 5 Ra effects of the experimental parameters and 3D surface graphs
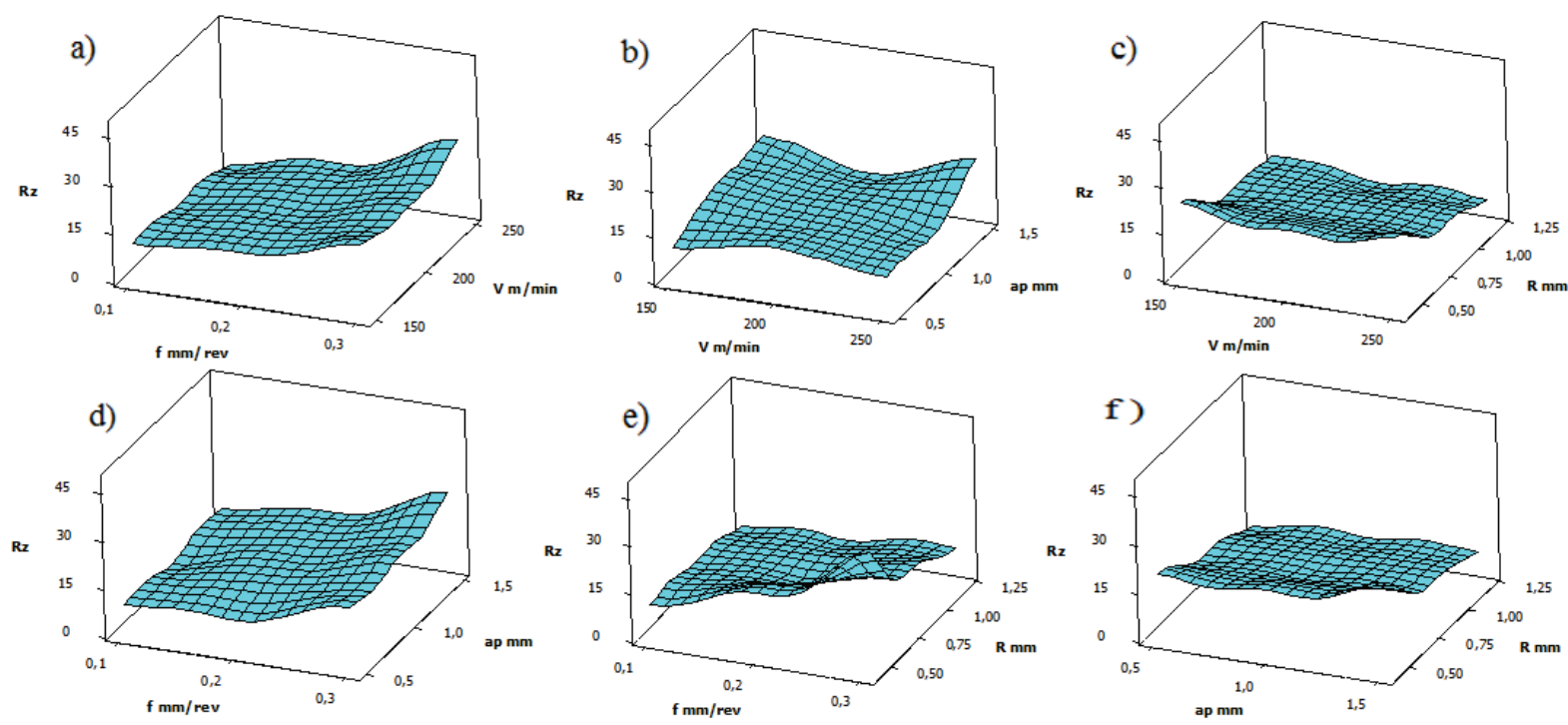

Figure $6 R z$ effects of the experimental parameters and 3D surface graphs 
Figs. 7 and 8 show the residual graphs of the model developed for the cutting parameters in the turning process to control the adequacy. Figs. 7 and 8 show that the residues follow an approximately straight line in the normal probability plot, and that the approximate symmetrical structure of the histogram shows that the residues are distributed normally. The normal probability graph of the remaining residues showed that the data conformed to the sample size rules and the confidence intervals and $p$-values on the straight line were correct.

Ideally, in the remaining and fitted plots, all points should fall randomly on both sides of the zero as in the recognizable pattern. Figs. 7 and 8 clearly show that all scores are placed on both sides of zero and that an unstable variance or opposite is not observed [37,38]. He confirmed that the residues were randomly distributed with constant variances. The plot against the residue showed the order of data collection and showed patterns at the time of observation and at points. Ideally, the remaining residue on the plot should fall randomly around the centerline. Figs. 7 and 8 clearly show that the residues close to each other are related and therefore not independent.

ANOVA was used in order to identify the effects of the cutting parameters used in the experimental design on the surface roughness ( $R a$ and $R z)$.

Table 7 Estimated Regression Coefficients for Ra and $R z$

\begin{tabular}{|c|c|c|c|c|c|c|c|c|c|}
\hline \multicolumn{5}{|c|}{$R a$} & \multicolumn{5}{|c|}{$R z$} \\
\hline Terms & Coef. & SE Coef. & $T$ & $p$ & Terms & Coef. & SE Coef. & $T$ & $p$ \\
\hline Constant & 1,73626 & 0,20023 & 8,671 & 0,000 & Constant & 9,0415 & 1,4261 & 6,340 & 0,000 \\
\hline$v$ & $-0,09543$ & 0,08175 & $-1,167$ & 0,266 & $v$ & $-0,4460$ & 0,5822 & $-0,766$ & 0,458 \\
\hline$f$ & 1,75319 & 0,08175 & 21,447 & 0,000 & $f$ & 6,5605 & 0,5822 & 11,268 & 0,000 \\
\hline$a p$ & 0,27893 & 0,08175 & 3,412 & 0,005 & $a p$ & 1,8869 & 0,5822 & 3,241 & 0,007 \\
\hline$R$ & $-1,54404$ & 0,08175 & $-18,888$ & 0,000 & $R$ & $-7,3258$ & 0,5822 & $-12,583$ & 0,000 \\
\hline$v \cdot v$ & 0,22817 & 0,14159 & 1,611 & 0,133 & $v \cdot v$ & 2,9845 & 1,0084 & 1,319 & 0,212 \\
\hline$f \cdot f$ & 0,59933 & 0,14159 & 4,233 & 0,001 & $f \cdot f$ & 1,3297 & 1,0084 & 2,960 & 0,012 \\
\hline ap ap & 0,11222 & 0,14159 & 0,793 & 0,443 & $a p \cdot a p$ & 0,9156 & 1,0084 & 0,908 & 0,382 \\
\hline$R \cdot R$ & 0,71889 & 0,14159 & 5,077 & 0,000 & $R \cdot R$ & 2,9334 & 1,0084 & 2,909 & 0,013 \\
\hline$v \cdot f$ & 0,34601 & 0,10340 & 3,346 & 0,006 & $v \cdot f$ & 2,4568 & 0,7365 & 3,336 & 0,006 \\
\hline$v \cdot a p$ & 0,38436 & 0,10340 & 3,717 & 0,003 & $v \cdot a p$ & 2,0988 & 0,7365 & 2,850 & 0,015 \\
\hline$v \cdot R$ & $-0,15733$ & 0,10340 & $-1,522$ & 0,154 & $v \cdot R$ & $-1,0686$ & 0,7365 & $-1,451$ & 0,172 \\
\hline$f \cdot a p$ & 0,17600 & 0,10340 & 1,702 & 0,114 & $f \cdot a p$ & 1,6106 & 0,7365 & 2,187 & 0,049 \\
\hline$f \cdot R$ & $-1,31890$ & 0,10340 & $-12,755$ & 0,000 & $f \cdot R$ & $-6,0887$ & 0,7365 & $-8,268$ & 0,000 \\
\hline$a p \cdot R$ & $-0,24814$ & 0,10340 & $-2,400$ & 0,034 & $a p \cdot R$ & $-1,6386$ & 0,7365 & $-2,225$ & 0,046 \\
\hline \multicolumn{2}{|c|}{$S=0,346815$} & $98,88 \%$ & \multicolumn{2}{|c|}{$R^{2}(a d j)=97,57 \%$} & \multicolumn{5}{|c|}{$\begin{array}{lll}S=2,47013 & R-S q=97,12 \% & R-S q(a d j)=93,75 \% \\
\end{array}$} \\
\hline
\end{tabular}

Table 8 Analysis of Variance for $R a$

\begin{tabular}{|c|c|c|c|c|c|c|c|}
\hline Source & $d f$ & Seq. SS & Adj. SS & Adj. MS & $F$ & $p$ & $\%$ Cont. \\
\hline$v$ & 1 & 0,164 & 0,164 & 0,1639 & 1,36 & 0,266 & 0,127 \\
\hline$f$ & 1 & 55,326 & 55,326 & 55,3258 & 459,97 & 0,000 & 43,002 \\
\hline$a p$ & 1 & 1,400 & 1,400 & 1,4004 & 11,64 & 0,005 & 1,088 \\
\hline$R$ & 1 & 42,913 & 42,913 & 42,9129 & 356,77 & 0,000 & 33,354 \\
\hline$v \cdot v$ & 1 & 0,312 & 0,312 & 0,3124 & 2,60 & 0,133 & 0,243 \\
\hline$f \cdot f$ & 1 & 2,155 & 2,155 & 2,1552 & 17,92 & 0,001 & 1,675 \\
\hline$a p \cdot a p$ & 1 & 0,076 & 0,076 & 0,0756 & 0,63 & 0,443 & 0,059 \\
\hline$R \cdot R$ & 1 & 3,101 & 3,101 & 3,1008 & 25,78 & 0,000 & 2,410 \\
\hline$v \cdot f$ & 1 & 0,968 & 1,347 & 1,3469 & 11,20 & 0,006 & 0,752 \\
\hline$v \cdot a p$ & 1 & 0,036 & 1,662 & 1,6620 & 13,82 & 0,003 & 0,028 \\
\hline$v \cdot R$ & 1 & 0,154 & 0,278 & 0,2785 & 2,32 & 0,154 & 0,120 \\
\hline$f \cdot a p$ & 1 & 0,348 & 0,348 & 0,3485 & 2,90 & 0,114 & 0,270 \\
\hline$f \cdot R$ & 1 & 19,569 & 19,569 & 19,5692 & 162,70 & 0,000 & 15,210 \\
\hline$a p \cdot R$ & 1 & 0,693 & 0,693 & 0,6927 & 5,76 & 0,034 & 0,539 \\
\hline Residual Error & 12 & 1,443 & 1,443 & 0,1203 & & & 1,122 \\
\hline
\end{tabular}

Table 9 Analysis of Variance for $R z$

\begin{tabular}{|c|c|c|c|c|c|c|c|}
\hline Source & $d f$ & Seq. SS & Adj. SS & Adj. MS & $F$ & $p$ & \% Cont. \\
\hline$v$ & 1 & 3,58 & 3,58 & 3,581 & 0,59 & 0,458 & 0,141 \\
\hline$f$ & 1 & 774,71 & 774,71 & 774,714 & 126,97 & 0,000 & 30,520 \\
\hline$a p$ & 1 & 64,09 & 64,09 & 64,086 & 10,50 & 0,007 & 2,525 \\
\hline$R$ & 1 & 966,02 & 966,02 & 966,021 & 158,32 & 0,000 & 38,057 \\
\hline$v \cdot v$ & 10,61 & 10,61 & 10,609 & 1,74 & 0,212 & 0,418 \\
\hline$f \cdot f$ & 1 & 53,44 & 53,44 & 53,445 & 8,76 & 0,012 & 2,105 \\
\hline$a p \cdot a p$ & 1 & 5,03 & 5,03 & 5,030 & 0,82 & 0,382 & 0,198 \\
\hline$R \cdot R$ & 1 & 51,63 & 51,63 & 51,630 & 8,46 & 0,013 & 2,034 \\
\hline$v \cdot f$ & 50,29 & 67,90 & 67,901 & 11,13 & 0,006 & 1,981 \\
\hline$v \cdot a p$ & 1 & 3,99 & 49,56 & 49,556 & 8,12 & 0,015 & 0,157 \\
\hline$v \cdot R$ & 1 & 5,32 & 12,85 & 12,847 & 2,11 & 0,172 & 0,210 \\
\hline$f \cdot a p$ & 1 & 29,18 & 29,18 & 29,184 & 4,78 & 0,049 & 1,150 \\
\hline$f \cdot R$ & 1 & 417,06 & 417,06 & 417,059 & 68,35 & 0,000 & 16,430 \\
\hline$a p \cdot R$ & 1 & 30,21 & 30,21 & 30,206 & 4,95 & 0,046 & 1,190 \\
\hline Residual Error & 12 & 73,22 & 73,22 & 6,102 & & & 2,885 \\
\hline Total & 26 & 2538,38 & & & & & 100 \\
\hline
\end{tabular}


Tab. 7 shows the results of ANOVA analysis, which was performed with $95 \%$ confidence interval for $R a$ and $R z$. When examining Tab. 7 it was observed that in terms of the significance value of $p<0,05, v$ parameter was not effective but $f, R$, and ap were effective. The contribution rates in Tab. 8 showed the significance degree of the machining parameters on $R a$. The most effective factor on $R a$ was found to be $f$, with contribution rate of $43,002 \%$, followed by $R$, with the rate of $33,354 \%$. The impact of the ap and $v$ parameters was $1,088 \%$ and $0,127 \%$, respectively. The most effective control parameters on $R z$ were $R$ at $38,057 \%, f$ at $30,520 \%$, ap at $2,525 \%$, and $v$ at $0,141 \%$, respectively (Tab. 9). When examining the interactions between the cutting parameters, it was found that the $f \cdot R$ contribution to $R a$ and $R z$ was $15,210 \%$ and $16,430 \%$, respectively. Figs. 5 and 6 show that the impact of the cutting speed on $R a$ and $R z$ was low, as is confirmed by the ANOVA tables.

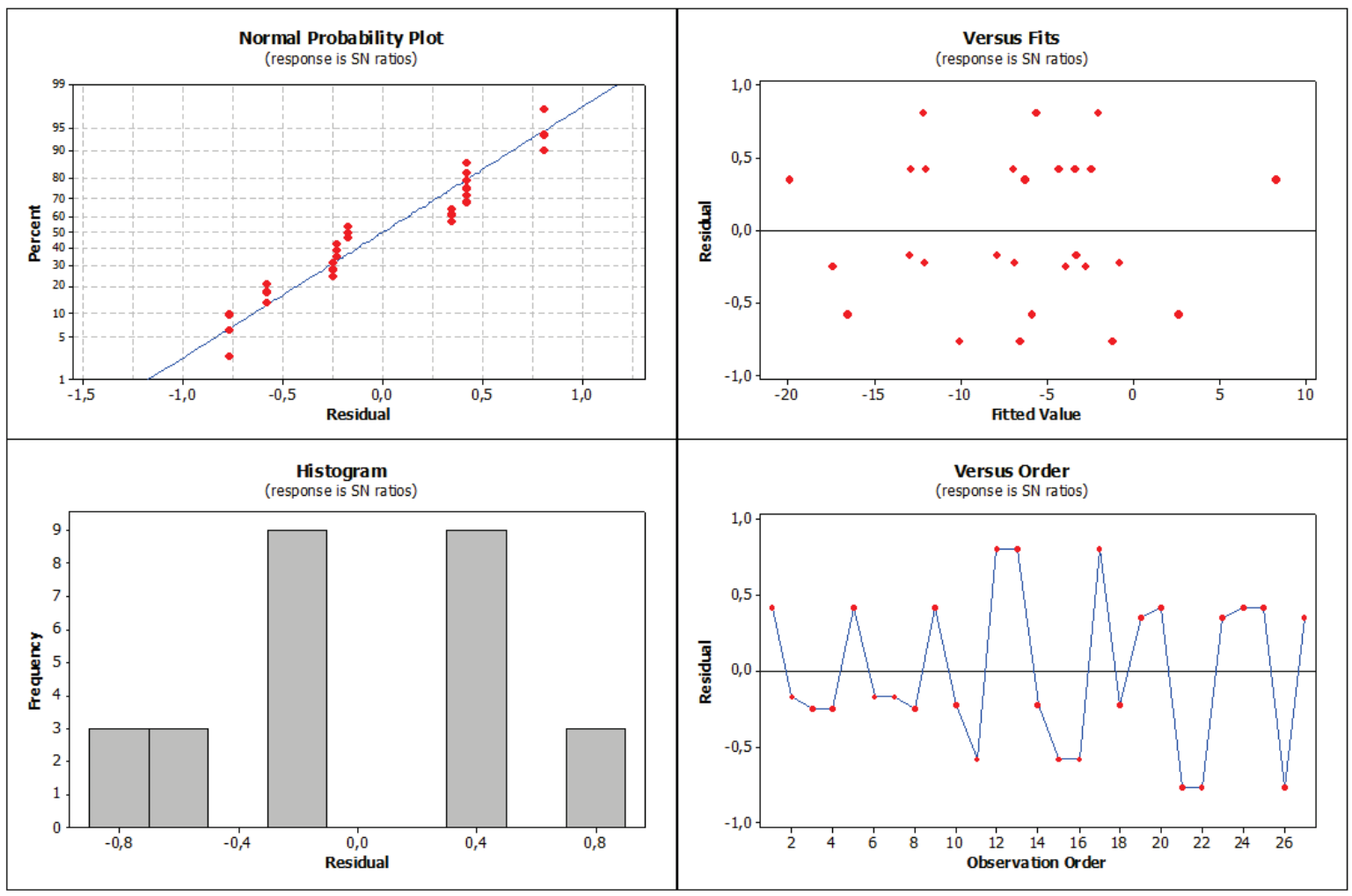

Figure 7 Residual plots of model for $R a$ in cutting parameters

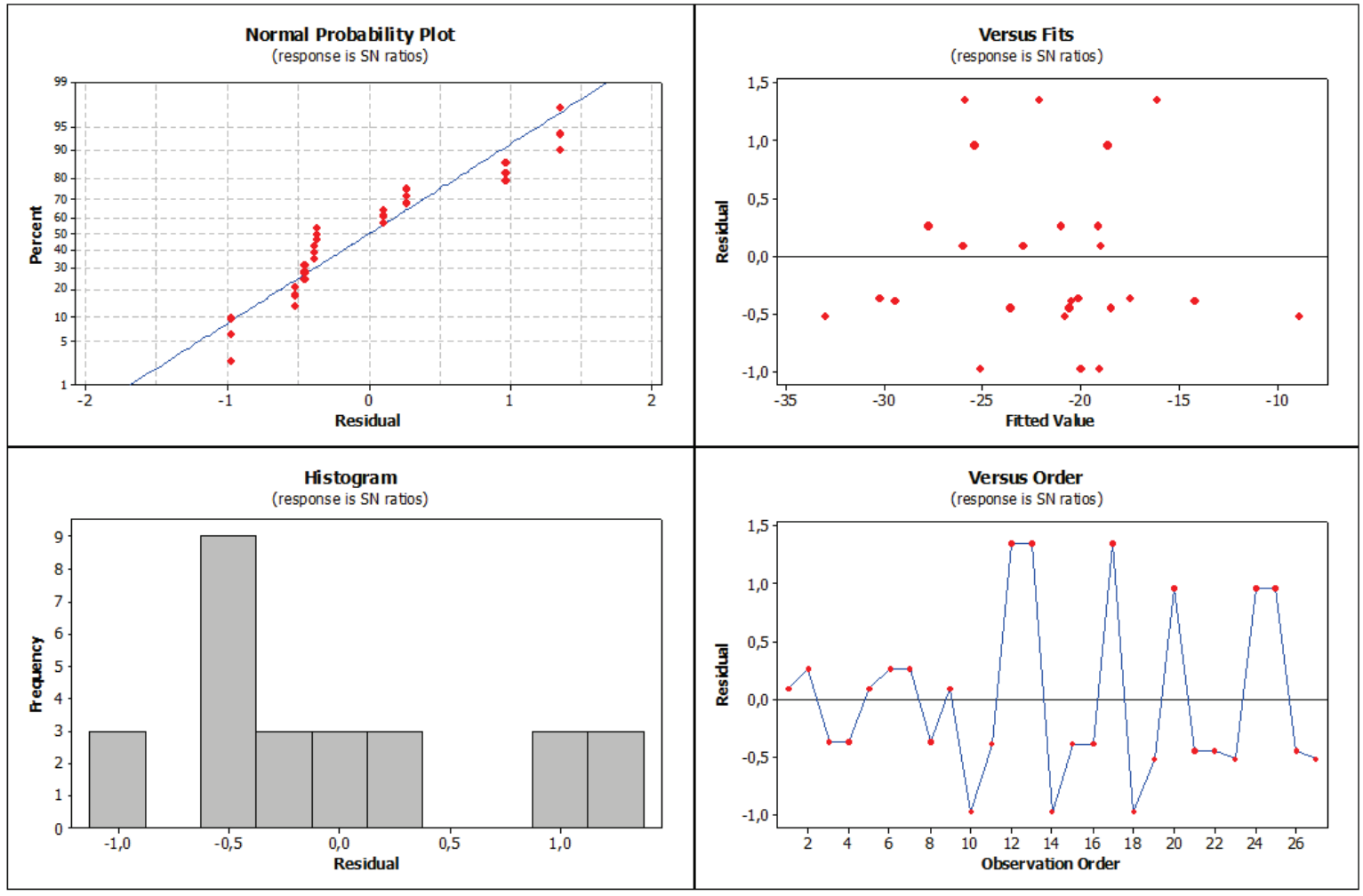

Figure 8 Residual plots of model for $R a$ in cutting parameters 
Fig. 9 shows a comparative graph for the results of the simulation surface roughness $(R a$ and $R z)$ obtained using Taguchi technique as well as the experimental results. When the figure was examined, it was seen that experimental and simulation results were compatible with one another.

The relationship between the surface roughness and machining parameters such as cutting speed $(v)$, feed $(f)$, depth of cut $(a p)$ and tool nose radius $(R)$ for second order response surface model has been developed using RSM from the observed data in uncoded units as follows. The predicted actual uncoded factors, i.e., surface roughness ( $R a$ and $R z$ ) were calculated using Eqs. (2) and (3) and plotted in Fig. 9.

$$
\begin{aligned}
& R a=9,53441-0,0613367 \cdot v+2,57615 \cdot f- \\
& -3,12627 \cdot a p-1,64046 \cdot R+9,12667 \cdot 10^{-5}+ \\
& +59,9333 \cdot f^{2}+0,448889 \cdot a p^{2}+4,49306 \cdot R^{2}+ \\
& +0,0692015 \cdot v \cdot f+0,0153745 \cdot v \cdot a p-0,00786667 \cdot v \cdot R+ \\
& +3,52 \cdot f \cdot a p-32,9724 \cdot f \cdot R-1,2407 \cdot a p \cdot R
\end{aligned}
$$$$
R z=60,6211-0,361151 \cdot v-62,4862 \cdot f+
$$$$
20,2296 \cdot a p+1,67371 \cdot R+0,000531881 \cdot v^{2}+
$$$$
+298,454 \cdot f^{2}+3,66237 \cdot a p^{2}+18,3339 \cdot R^{2}+
$$$$
+0,491351 \cdot v \cdot f+0,0839523 \cdot v \cdot a p-0,0534315 \cdot v \cdot R+
$$

$+32,2126 \cdot f \cdot a p-152,217 \cdot f \cdot R-8,19289 \cdot a p \cdot R$

Optimal results of surface roughness ( $R a$ and $R z)$ values were obtained in the experimental study conducted using the Taguchi optimization method. ANOVA analyses were then performed, and percentage distributions of the parameters having an effect on the results were determined. The final step of the optimization operation is to conduct confirmation experiment and to test validity of the optimization operation. While the parameter group yielding the optimal surface roughness value as a result of the Taguchi optimization may be sometimes one of the current experiments, it may also be an experiment except for the experiments done. In this study, apart from the existing experiments that were done for $R a$ and $R z$, the validation experiments were repeated three times with the $v 3 f 2 \operatorname{ap} 2 R 1(v=250 \mathrm{~m} / \mathrm{min}, f=0,2 \mathrm{~mm} / \mathrm{rev}$, ap $=1 \mathrm{~mm}$, $R=0,4 \mathrm{~mm}$ ) cutting parameters three times and their arithmetic averages were collected. When the experimental results were compared with the estimated results as a result of the confirmation experiments, it was observed that high convergence values for $R a$ of $97,33 \%$ and $R z$ of $96,63 \%$ were obtained (Tab. 10). In this context, it was remarkable that the difference between the results of the confirmation experiment and the results obtained from the Taguchi approach was negligible.

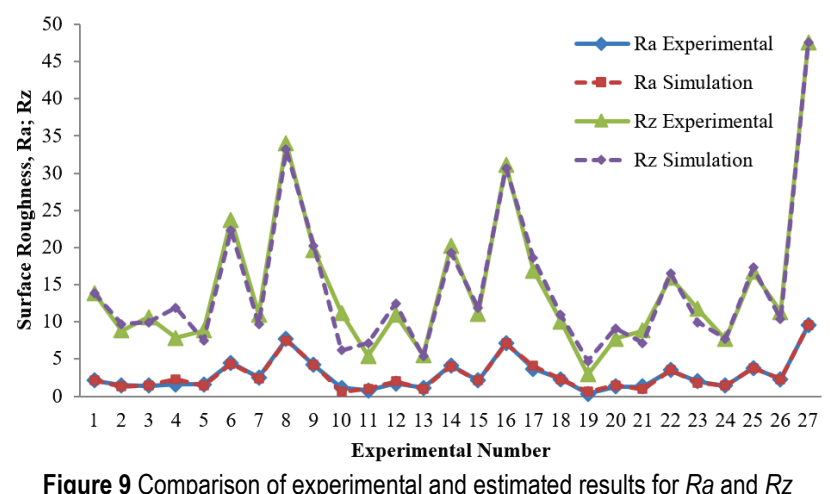

Figure 9 Comparison of experimental and estimated results for $R a$ and $R z$

Table 10 Comparison of the prediction model and experimental results

\begin{tabular}{|c|c|c|c|c|c|}
\hline Parameters & Parameters levels & \multicolumn{2}{|c|}{ Values of $R a / \mu \mathrm{m}$} & \multicolumn{2}{c|}{ Values of $R z / \mu \mathrm{m}$} \\
\hline Cutting Speed $/ \mathrm{m} / \mathrm{min}$ & 250 & Prediction & Experimental & \multicolumn{2}{|c|}{ Prediction } \\
\hline Feed rate $/ \mathrm{mm} / \mathrm{rev}$ & 0,2 & \multirow{2}{*}{4,2906} & \multirow{2}{*}{4,408} & \multirow{2}{*}{21,3635} & 20,645 \\
\hline Depth of cut / mm & 1 & & & & \\
\hline Tool nose radius $/ \mathrm{mm}$ & 0,4 & & & \\
\hline
\end{tabular}

\section{CONCLUSIONS}

In this study, the effects of different cutting speeds, feed rates, depths of cut, and tool nose radius on surface roughness in turning of St-37 steel were investigated. The following results were obtained as a result of the study using the Taguchi method in optimization of the machining parameters:

- According to the results of variance analysis of the $S / N$ ratios, the order of importance of the variables being effective on surface roughness $(R a)$ was $f, R, a p$ and $v$. On the other hand, the order of importance of the effective variables for $R z$ was $R, f$, ap and $v$ respectively. In the optimization made with the help of $S / N$ analysis, the optimum machining parameters yielding the lowest surface roughness value $(R a=$ $0,369 \mu \mathrm{m}$ and $R z=2,957 \mu \mathrm{m}$ ) were found as follows: $250 \mathrm{~m} / \mathrm{min}$ for cutting speed, $0,5 \mathrm{~mm}$ for depth of cut, $0,1 \mathrm{~mm} / \mathrm{rev}$ for feed rate and $1,2 \mathrm{~mm}$ for tool nose radius.
- In the evaluation of ANOVA results, the contribution of $f, R$, ap and $v$ to experimental results on $R a$ was as follows: $43,002 \%, 33,354 \%, 1,088 \%$ and $0,127 \%$, respectively. Likewise, the contributions of $R, f, a p$, and $v$ on $R z$ were as follows: $38,057 \%, 30,520 \%$, $2,525 \%$, and $0,141 \%$, respectively. The ANOVA results also revealed that the most effective parameter on both $R a$ and $R z$ was $f$ and $R$, respectively. Similarly, the $f \cdot R$ interaction contributed greatly to the experimental results. When the effect of cutting parameters on the surface roughness was examined in terms of the $p$ significance value $(p<0,05)$, it was determined that $v$ was insignificant and $f$, ap, and $R$ were significant.

- When the effect of cutting parameters on surface roughness was examined, it was found that as the $f$ and ap value increased, $R a$ and $R z$ increased, and as $R$ increased, $R a$ and $R z$ decreased. The effect of $v$ was rather low in this study. 
- As a result of the confirmation experiments, high convergence values were determined for $R a$ and $R z$ at $97,33 \%$ and $96,63 \%$, respectively.

\section{REFERENCES}

[1] Ahmed, G. S., Quadri, S. S. H., \& Mohiuddin, M. S. (2015). Optimization of feed and radial force in turning process by using Taguchi design approach. Materials Today: Proceedings, 4, 3277-3285. https://doi.org/10.1016/..matpr.2015.07.141

[2] Özel, T. \& Karpat, Y. (2005). Predictive Modeling of Surface Roughness and Tool Wear in Hard Turning Using Regression and Neural Networks. International Journal of Machine Tools \& Manufacture, 45, 467-479. https://doi.org/10.1016/j.jimachtools.2004.09.007

[3] Sterpin Valic, G., Cukor, G., Jurkovic, Z., \& Brezocnik, M. (2019). Multi-Criteria Optimization of Turning of Martensitic Stainless Steel for Sustainability. International Journal of Simulation Modelling, 18(4), 632-642. https://doi.org/10.2507/IJSIMM18(4)495

[4] Senthilkumar, N., Sudha, J., \& Muthukumar, V. (2015). A grey-fuzzy approach for optimizing machining parameters and the approach angle in turning AISI 1045 steel. Advances in Production Engineering \& Management, 10(4), 195-208. http://dx.doi.org/10.14743/apem2015.4.202

[5] Sung, A. N., Loh, W. P., \& Ratnam, M. M. (2016). Simulation Approach for Surface Roughness Interval Prediction in Finish Turning. International Journal of Simulation Modelling, 15(1), 42-55. https://doi.org/10.2507/IJSIMM15(1)4.320

[6] Cakir, M. C., Ensarioglu, C., \& Demirayak, I. (2009). Mathematical modeling of surface roughness for evaluating the effects of cutting parameters and coating material. Journal of Materials Processing Technology, 209, 102109. https://doi.org/10.1016/j.jmatprotec.2008.01.050

[7] Günay, M. (2013). Optimization with Taguchi method of cutting parameters and tool nose radius in machining of AISI 316L steel. Journal of the Faculty of Engineering and Architecture of Gazi University, 28, 437-444.

[8] Kurt, A. \& Şeker, U. (2005). The effect of chamfer angle of polycrystalline cubic boron nitride cutting tool on the cutting forces and the tool stresses in finishing hard turning of AISI 52100 steel. Materials \& design, 26, 351-356. https://doi.org/10.1016/j.matdes.2004.06.022

[9] Yang, A., Han, Y., Pan, Y., Xing, H., \& Li, J. (2017). Optimum surface roughness prediction for titanium alloy by adopting response surface methodology. Results in Physics, 7, 1046-1050. https://doi.org/10.1016/j.rinp.2017.02.027

[10] Ramesh, S., Karunamoorthy, L., \& Palanikumar, K. (2012). Measurement and analysis of surface roughness in turning of aerospace titanium alloy (gr5). Measurement, 45, 12661276. https://doi.org/10.1016/j.measurement.2012.01.010

[11] Davim, J. P. (2001). A note on the determination of optimal cutting conditions for surface finish obtained in turning using design of experiments. Journal of Materials Processing Technology, 116, 305-308. https://doi.org/10.1016/S0924-0136(01)01063-9

[12] Günay, M. \& Yücel, E. (2013). Application of Taguchi method for determining optimum surface roughness in turning of high-alloy white cast iron. Measurement, 46, 913919. https://doi.org/10.1016/j.measurement.2012.10.013

[13] Bouache, K., Yallese, M. A., Mabrouki, T., \& Rigal, J. F. (2010). Statistical analysis of surface roughness and cutting forces using response surface methodology in hard turning of AISI 52100 bearing steel with CBN tool. Int. Journal of Refractory Metals \& Hard Materials, 28, 349-361. https://doi.org/10.1016/j.jirmhm.2009.11.011
[14] Lalwani, D. I., Mehta, N. K., \& Jain, P. K. (2008). Experimental investigations of cutting parameters influence on cutting forces and surface roughness in finish hard turning of MDN250 steel. Journal of materials processing technology, 206, 167-179. https://doi.org/10.1016/j.jmatprotec.2007.12.018

[15] Asiltürk, İ. \& Çunkaş, M. (2011). Modeling and prediction of surface roughness in turning operations using artificial neural network and multiple regression method. Expert Systems with Applications, 38, 5826-5832. https://doi.org/10.1016/j.eswa.2010.11.041

[16] Agrawal, A., Goel, S., Rashid, W. B., \& Price, M. (2015). Prediction of surface roughness during hard turning of AISI 4340 steel (69 HRC). Applied Soft Computing, 30, 279-286. https://doi.org/10.1016/j.asoc.2015.01.059

[17] Routara, B. C., Sahoo, A. K., Parida, A. K., \& Padhi, P. C. (2012). Response Surface Methodology and Genetic Algorithm used to optimize the Cutting condition for Surface Roughness Parameters in CNC Turning. Procedia Engineering, 38, 1893-1904. https://doi.org/10.1016/j.proeng.2012.06.232

[18] Selveraj, D. P. \& Chandramohan, P. (2010). Optımızatıon of Surface Roughness of AISI 304 Austenitic Stainless Steel in Dry Turning Operation Using Taguchi Design Method. Journal of Engineering Science and Technology, 5, 293-301.

[19] Sahoo, P. (2011). Optimization of Turning Parameters for Surface Roughness Using RSM and Ga. Advances in Production Engineering \& Management, 6, 197-208.

[20] Neşeli, S., Yaldız, S., \& Türkeş, E. (2011). Optimization of tool geometry parameters for turning operations based on the response surface methodology. Measurement, 44, 580-587. https://doi.org/10.1016/j.measurement.2010.11.018

[21] Singh, D. \& Rao, P. V. (2007). A surface roughness prediction model for hard turning process. Int. J. Adv. Manuf. Technol., 32, 1115-1124. https://doi.org/10.1007/s00170-006-0429-2

[22] Aouici, H., Yallese, M. A., Chaoui, K., Mabrouki, T., \& Rigal, J. F. (2012). Analysis of surface roughness and cutting force components in hard turning with CBN tool: prediction model and cutting conditions optimization. Meas. J. Int. Meas. Confed., 45, 344-353. https://doi.org/10.1016/j.measurement.2011.11.011.

[23] Makadia, A. J. \& Nanavati, J. I. (2013). Optimisation of machining parameters for turning operations based on response surface methodology. Measurement, 46, 15211529. https://doi.org/10.1016/j.measurement.2012.11.026

[24] Wang, M. Y. \& Lan, T. S. (2008). Parametric optimization on multi-objective precision turning using grey relational analysis. Inf. Technol. J., 7, 1072-1076. https://doi.org/10.1016/j.proeng.2014.12.253

[25] Noordin, M. Y., Venkatesh, V. C., Sharif, S., Elting, S., \& Abdullah, A. (2004). Application of response surface methodology in describing the performance of coated carbide tools when turning AISI 1045 steel. Journal of Materials Processing Technology, 145, 46-58. https://doi.org/10.1016/S0924-0136(03)00861-6

[26] Deepakkumar, H. P. \& Sadaiah, M. (2011). Investigations on finish turning of AISI 4340 steel in different cutting environments by $\mathrm{CBN}$ insert. International Journal of Engineering Science and Technology, 3, 7690-7706.

[27] Xavior, M. A. \& Adithan, M. (2009). Determining the influence of cutting fluids on tool wear and surface roughness during turning of AISI 304 austenitic stainless steel. Journal of materials processing technology, 209, 900909. https://doi.org/10.1016/j.jmatprotec.2008.02.068

[28] Groover, M. P. (2010). Fundamentals of modern manufacturing: materials, processes and systems, 4 th ed.

[29] Akkurt, M. (2004). Talaş kaldırma yöntemleri ve Takım tezgâhları, Birsen Yayın Evi Istanbul. 
[30] Cogun, C. \& Ozses, B. (2002). Effect of Machining Parameters on Surface Roughness in Cnc Machine Tools. Gazi Univ. Muh. Mim. Fak. Der., 17, 59-67.

[31] Taguchi, G. \& Konishi, S. (1987). Orthogonal Arrays and Linear Graphs, American Supplier Institute.

[32] Taguchi, G., Elsayed, E., \& Hsiang, T. (1989). Quality Engineering in Production Systems. McGraw-Hill, Books, New York,

[33] Köklü, U. (2013). Optimisation of machining parameters in interrupted cylindrical grinding using the Greybased Taguchi method. International Journal of Computer Integrated Manufacturing, 26, 696-702. https://doi.org/10.1080/0951192X.2012.749537

[34] Ross, P. J. (1988). Taguchi Techniques for Quality Engineering, Mc-Graw-Hill, New York.

[35] Korkut, I., Boy, M., Karacan, I., \& Seker, U. (2007). Investigation of Chip-back temperature during machining depending on cutting parameter. Materials and Design, 28, 2329-2335. https://doi.org/10.1016/j.matdes.2006.07.009

[36] Outeiro, J. C., Umbrello, D., \& M'Saoubi, R. (2006). Experimental and numerical modelling of the residual stresses induced in orthogonal cutting of AISI 316L steel. International Journal of Machine Tools and Manufacture, 46, 1786-1794. https://doi.org/10.1016/j.jimachtools.2005.11.013

[37] Yoon, H. S., Wu, R., Lee, T. M., \& Ahn, S. H. (2011). Geometric Optimization of Micro Drills using Taguchi Methods and Response Surface Methodology. Int. J. Precis. Eng. Manuf., 12, 871-875. https://doi.org/10.1007/s12541-011- 0116-6

[38] Kumar, S. N. \& Andhare, A. B. (2019). Multiobjective optimization for improving machinability of Ti-6Al-4V using RSM and advanced algorithms. Journal of Computational Design and Engineering 6 1-12.

https://doi.org/10.1016/j.jcde.2018.04.004

\section{Contact information:}

Mustafa ÖZDEMiR, PhD, Asst. Prof.

Bozok University,

Machine and Metal Technology Department,

Vocational High School,

Erdogan Akdag Kampüsü

Atatürk Yolu 7. Km 66900 Yozgat, Turkey

E-mail: mustafa.ozdemir@bozok.edu.tr 